\title{
Rituais fúnebres na pandemia de COVID-19 e luto: possíveis reverberaçōes ${ }^{a}$
}

\author{
Funeral rites in the COVID-19 pandemic and grief: possible reverberations
}

Rituales funerarios en la pandemia de COVID-19 y dolor: posibles repercusiones

Maria Eduarda Padilha Giamattey ${ }^{1}$ (]) Joselma Tavares Frutuoso ${ }^{2}$ (D)

Maria Lígia dos Reis Bellaguarda ${ }^{3}$ (I) Ivânia Jann Luna² $\mathbb{1}$

1. Universidade Federal de Santa Catarina, Programa de Pós-Graduação em Saúde Mental e Atenção Psicossocial. Florianópolis, SC, Brasil.

2. Universidade Federal de Santa Catarina, Departamento de Psicologia. Florianópolis, SC, Brasil.

3. Universidade Federal de Santa Catarina, Departamento de Enfermagem. Florianópolis, SC, Brasil.

Autor correspondente:

Maria Eduarda Padilha Giamattey.

E-mail: mepadilhag@gmail.com

Recebido em 17/05/2021.

Aprovado em 03/08/2021.

DOI:https://doi.org/10.1590/2177-9465-EAN-2021-0208

\section{Resumo}

Objetivo: compreender a ausência de rituais fúnebres na pandemia de COVID-19 no processo de viver o luto das famílias brasileiras que perderam entes queridos por COVID-19. Método: pesquisa qualitativa documental realizada em três jornais disponibilizados online. Foram analisadas 67 reportagens, divididas em duas categorias; a primeira trata dos sofrimentos psicológicos derivados do isolamento social, como ansiedade, depressão, solidão e medo; e a segunda trata das diferentes manifestações do luto e o efeito psicológico das perdas em meio à pandemia. Resultado: a ritualização da morte é indissociável do processo de elaboração das perdas. A ausência de rituais fúnebres, aliada ao distanciamento social, repercute de forma desafiadora para a sociedade e para os profissionais da saúde mental. Estratégias não presenciais de demonstração de afeto e elaboração da perda podem amenizar o isolamento imposto pela pandemia. Conclusões e implicações para a prática: o processo de viver humano é repleto de ritos de passagem e a ritualística na morte-morrer se mostra necessária para a vivência da despedida, da certeza do distanciamento ocorrido entre entes e família. Implica em modos resolutivos de registro emocional, mental e mesmo físico da expressão pública de sofrimento do enlutado e do não esquecimento do Ser à morte. Impacta na prática assistencial para o acolhimento, orientação e elaboração das perdas para a manutenção de vida saudável das pessoas enlutadas, o que propõe argumentos teórico-reflexivos no cuidado em saúde mental e na guarida de pessoas enlutadas decorrentes da pandemia.

Palavras-chave: Luto; Rituais Fúnebres; Infecções por Coronavirus; Morte; Psicologia.

\section{Abstract}

Objective: to understand the absence of funeral rituals in the process of living the grief process of Brazilian families who lost loved ones by COVID-19. Method: this is a qualitative documental research carried out in three newspapers available online. Sixty-seven reports were analyzed, divided into two categories; the first deals with psychological suffering derived from social isolation, such as anxiety, depression, loneliness and fear; and the second deals with the different manifestations of grief and the psychologica effect of losses amidst the pandemic. Result: the ritualization of death is inseparable from the process of elaboration of the losses. The absence of funeral rituals combined with social dictatorship can have a challenging impact on society and mental healthcare professionals. Non-presential strategies for showing affection and elaborating the loss can ease the isolation imposed by the pandemic Conclusions and implications for practice: the human living process is full of rites of passage and death-dying rituals prove to be necessary for the experience of farewell, of the certainty of the distance between loved ones and family. It implies resolving modes of emotional, mental and even physical recording of the public expression of the griever's suffering and not forgetting the Being's to death. It impacts care practice for reception, guidance and elaboration of losses for the maintenance of a healthy life for grievers, which proposes theoretical-reflective arguments in mental healthcare and in the shelter of grievers resulting from the pandemic.

Keywords: Bereavement; Funeral Rites; Coronavirus Infections; Death; Psychology.

\section{Resumen}

Objetivo: comprender la ausencia de rituales funerarios en el proceso de dolor de las familias brasileñas que perdieron a sus seres queridos por COVID-19. Método: una investigación documental cualitativa realizada en tres periódicos disponibles en línea. Se analizaron 67 informes, divididos en dos categorías; el primero trata sobre el sufrimiento psicológico derivado del aislamiento social, como la ansiedad, la depresión, la soledad y el miedo; y el segundo trata de las diferentes manifestaciones del dolor y e efecto psicológico de las pérdidas en medio de la pandemia. Resultado: la ritualización de la muerte es inseparable del proceso de elaboración de las pérdidas. La ausencia de rituales funerarios combinada con la dictadura social puede tener un impacto desafiante en la sociedad y los profesionales de la salud mental. Las estrategias no presenciales para mostrar afecto y explicar la pérdida pueden aliviar el aislamiento impuesto por la pandemia. Conclusiones e implicaciones para la práctica: el proceso de vivir humano está lleno de ritos de paso y los rituales de la muerte-morir resultan necesarios para la experiencia de la despedida, de la certeza de la distancia entre los seres queridos y la familia. Implica resolver modos de registro emocional, mental e incluso físico de la expresión pública del sufrimiento del doliente y del no olvido del Ser hasta la muerte. Incide en la práctica asistencial para la recepción, orientación y elaboración de las pérdidas para el mantenimiento de una vida sana de las personas en dolor, el cual propone argumentos teórico-reflexivos en la atención de la salud mental y en el refugio de personas en dolor producto de la pandemia.

Palabras clave: Aflicción; Ritos Fúnebres; Infecciones por Coronavirus; Muerte; Psicología 


\section{INTRODUÇÃO}

No ano de 2020, o mundo se encontrou diante de um inimigo comum: a doença causada pelo vírus SARS-CoV-2, abreviação de Coronavirus Disease, que logo seria chamada apenas de COVID-191. Inicialmente reportada na província de Wuhan, na China, em dezembro de 2019, a doença foi caracterizada pela Organização Mundial de Saúde (OMS) como uma emergência de saúde pública de importância internacional em 30 de janeiro de 2020 , quando todas as 34 províncias do país reportaram casos da doença e o total de infectados já ultrapassava o número atingido pela Síndrome Respiratória Aguda Grave (SARS) no ano de $2003^{2}$. Em 11 de março de 2020, frente ao rápido crescimento do número de infectados e mortes pela COVID-19 nos mais diferentes países, a OMS passou a declarar a situação como uma pandemia ${ }^{3}$.

A geração atual, em qualquer faixa do desenvolvimento humano, nunca viveu algo semelhante e com uma letalidade tão brutal em curto espaço de tempo, referindo-se à Gripe Espanhola, que durou de 1918 a 1920 e infectou cerca de 100 milhões de pessoas no mundo todo e levou à óbito entre 17 e 50 milhões de vidas, tornando essa uma das epidemias mais mortais da história. Os danos colaterais e a mortalidade da pandemia de COVID-19 derrubaram este argumento ${ }^{4}$.

Medidas globais de distanciamento social foram as medidas imediatas para tentar impedir a rápida disseminação da doença e a preservação dos sistemas de saúde para o atendimento da crescente demanda por leitos hospitalares. A recuperação do quadro de sintomas agudos da COVID-19, em ambiente hospitalar, pode requerer vários dias ou meses de internação. Logo, as medidas de distanciamento social não têm o intuito de apenas parar a transmissão do vírus, mas sim de achatar a curva de contágio para que os leitos hospitalares não atingissem a capacidade máxima, o que levaria a um colapso no sistema de saúde do país.

Diferentes abordagens foram utilizadas para combater a infecção pela COVID-19, entre elas, aquelas promovidas pela Telemedicina como: obter um diagnóstico mais rapidamente e iniciar o tratamento e acompanhamento no domicílio, evitando a sobrecarga nos hospitais; minimizar a circulação de pessoas nos ambientes públicos pelo contato telefônico; prevenir o risco de contágio, evitando o contato físico direto; reduzir custos com equipamentos de proteção individual; e até mesmo treinamento de profissionais de saúde à distância; além disso, fornece atualizações regulares informações sobre a evolução da pandemia ${ }^{5}$. São medidas que favorecem o distanciamento social, ao mesmo tempo que atuam em benefício da população que necessita de apoio e informações mais concretas e adequadas.

Durante um tempo, os estados brasileiros conseguiram criar e aderir a medidas restritivas de aglomeração. Tais medidas foram suspensão temporária de escolas, universidades, transportes públicos, proibição de qualquer atividade que envolvesse aglomerações de mais de dez pessoas, isolamento de casos suspeitos, obrigatoriedade do uso de máscaras e controle de temperatura em ambientes públicos e fechados, como shoppings centers, academias e supermercados ${ }^{6}$. Porém, com a ausência de fortalecimento público, governamental e financeiro dessas medidas, elas foram diluindo ao longo do tempo, agregada à derrocada dos serviços de saúde, aumento do número de mortes e contágio exacerbado em todo país ${ }^{7}$.

A pandemia causada pelo novo coronavírus não é apenas uma crise epidemiológica, é também psicológica. A politização da COVID-19, as mensagens sobre máscaras e o impacto do distanciamento social na saúde mental deixaram claro o quão importante é a psicologia durante uma pandemia. Independentemente da exposição à doença, a situação atual pode provocar sentimentos como estresse, ansiedade, tristeza, desamparo, raiva e impotência, dentre outros ${ }^{8}$. Pesquisas já revelaram o profundo e amplo espectro de impactos psicológicos que epidemias podem infringir nas pessoas, variando do desencadeamento de novos quadros clínicos de sofrimento psíquico naqueles que previamente não tinham históricos até o agravamento das condições daqueles que já possuíam algum quadro de sofrimento psíquico².

Em uma pandemia, vivenciamos tanto as perdas de vidas humanas quanto as perdas de empregos, de interações sociais presenciais e rotinas. Ou seja, estamos vivendo diferentes formas de contato com os significados da morte e do luto em larga escala social, desde a privação coletiva da convivência com as pessoas até a perda da própria saúde ou de entes queridos, caso haja contágio pelo vírus e a ocorrência da morte. Destacam-se também as mudanças de estilos de vida a partir da desestabilização dos referenciais sociais, como trabalho, sistema de saúde, educação, economia ou conexões sociais e familiares ${ }^{9,10}$.

A morte necessariamente vem acompanhada do luto e ambos são fenômenos que acontecem com todos os seres humanos. Por se tratar de fenômenos universais e inevitáveis, poderíamos pensar que eles seriam enfrentados com naturalidade. No entanto, a morte ocupa um lugar de exclusão na sociedade ocidental, em que não se fala sobre o assunto, ou então, ao citálo, usam-se vocábulos para substituir e amenizar o real sentido como: passagem, descanso, ou então expressões populares ora atreladas à religião e espiritualidade como 'bateu as botas', 'foi dessa para uma melhor', 'descansou, está com Deus', 'está em paz', dentre outras ${ }^{11}$.

Após passar por algumas ou todas as fases do desenvolvimento humano, a morte marca o final de um processo único e individual do desenvolvimento de cada ser humano. A morte de alguém significativo desperta o conflito primordial do processo de luto, viver o sofrimento pela perda e, ao mesmo tempo, seguir em frente $^{12}$. Tal definição está presente na cartilha intitulada "Processo de luto na COVID-19", produzida durante a pandemia pela Fundação Oswaldo $\mathrm{Cruz}^{13}$.

O significado, as explicações, os rituais de passagem entre a vida e a morte e o processo de enlutamento variam conforme cada sociedade e suas diferenças culturais, cosmológicas e religiosas, bem como as circunstâncias em que as mortes ocorrem. Cada sociedade é responsável por estabelecer os códigos culturais aceitáveis para o estabelecimento de rituais fúnebres de seus entes queridos, que envolvem desde cerimônias de despedidas, homenagens, até modos diversos de tratamento dos corpos, como o enterro ou a cremação ${ }^{13: 2}$. 
Entende-se o luto como um processo natural de resposta a um rompimento de vínculo mediante a perda de alguém ou algo significativo na vida ${ }^{14}$. Neste sentido, a prática dos rituais se relaciona, diretamente, com as mudanças no ciclo vital e entendemos que o indivíduo se modifica à medida que ultrapassa as fronteiras que demarcam a passagem de uma posição, estados e status para a seguinte. Para além da imensa variedade de rituais existentes na vida humana, jazem as formas que permeiam o senso de comunidade específico de cada sociedade, ao mesmo tempo que revelam a forma com que esta se estrutura e reestrutura diante das mudanças que ocorrem no percurso da vida ${ }^{15}$.

A pandemia veio de uma forma avassaladora, atropelando a organização e realização dos rituais funerários e de despedidas das famílias e seus desdobramentos: funeral, cremação, sepultamento, luto. Exemplo disso observamos na abertura de valas comuns nas cidades mais impactadas pela pandemia devido à incapacidade dos serviços funerários de atenderem o alto número de óbitos em curto tempo causados pela COVID-19, gerando assim um cenário de enterros coletivos a céu aberto. Além de que, nas cidades onde o serviço funerário ainda tem capacidade de atender às demandas de enterros e velórios, a facilidade do contágio pelo vírus impossibilitou que esses eventos ocorressem com mais de dez pessoas presentes, durando apenas uma hora ou menos. Foram surgindo novos modos de se despedir dos entes queridos; em alguns lugares, estão sendo organizados os chamados 'velórios virtuais', orações por aplicativo e grupos de apoio online: o ‘novo' luto durante a pandemia como um modo de aproximar afetivamente as pessoas e permitir a despedida ${ }^{16}$.

Os ritos fúnebres coincidem com a fase inicial do luto. É possível encará-los como espaços potentes para a elaboração da perda, contribuindo para o bem estar psíquico, pois, mesmo sofrendo com a perda, o ritual auxilia na organização psíquica da vida sem o ente querido. Além disso, o ritual em si é organizado de tal maneira que a despedida possa ser feita em conjunto por todos que estabeleceram algum tipo de vínculo afetivo com a pessoa que faleceu ${ }^{17}$.

Apesar de não haver uma lacuna teórica no que tange à importância dos rituais fúnebres no processo do luto, cremos que a interface deste tema (impedimento de rituais fúnebres) e o contexto específico da pandemia são um espaço-tempo a ser investigado. Este estudo evidencia a oportunidade de agregar em tempo real o estudo como potencial de desenvolvimento da temática. Diante disso, apresentamos o objetivo de compreender as reverberações da ausência de ritual fúnebre no processo de viver o luto das famílias brasileiras que perderam um ente querido pela COVID-19.

\section{MÉTODO}

A abordagem metodológica é de cunho qualitativo com pesquisa documental. Essa escolha se deu devido à impossibilidade de a coleta de dados empíricos ocorrer presencialmente, por conta das medidas de isolamento social. A pesquisa qualitativa tem como objetivo entender com profundidade como os fenômenos acontecem, e não apenas quantificar números e incidências ${ }^{18}$.

Este estudo é considerado de caráter documental. A pesquisa documental é aquela em que os dados obtidos são estritamente provenientes de documentos, com o objetivo de extrair informações neles contidas, a fim de compreender um fenômeno ${ }^{19,20}$. As fontes documentais pesquisadas neste estudo foram constituídas pela mídia jornalística ${ }^{21}$. Foi elencada a mídia jornalística disponibilizada online, de circulação ampla e de cobertura no Brasil, América Latina e Iberoamérica. O primeiro jornal selecionado foi aquele que é considerado um dos principais meios de comunicação impressa no país ${ }^{22}$, A Folha de São Paulo, e o segundo jornal é disponibilizado exclusivamente online e em mais de um idioma, cobrindo os países da América Latina e Iberoamérica, o El País. Considerando que, na busca piloto, encontramos poucas reportagens na Folha de São Paulo, decidimos incluir um terceiro jornal brasileiro de circulação online e impressa, do Rio de Janeiro, o jornal O Globo.

Como recorte temporal, optamos pelo período de março a maio de 2020. Justificamos essa escolha em decorrência de as medidas de distanciamento social terem sido iniciadas no país no mês de março. Assim, decidimos por limitar a coleta de dados até maio, a fim de podermos levantar um número suficiente de dados para análise e discussão dos principais achados. Os dados foram coletados pela pesquisadora principal entre 17 de março e 31 de maio, tempo disponibilizado para a busca e seleção das matérias foi em média de 540 horas.

Para desenvolvimento deste estudo, foi realizada uma busca nas bases de dados online dos jornais selecionados, com as seguintes palavras de busca: morte; enterro; funeral; pandemia luto; coronavírus; família, com amplo escopo pelas sessões dos jornais. A sessão obituária foi descartada, a priori, por ela ser predominantemente direcionada a homenagens e locais de velório. Os critérios de inclusão foram: aderência com a temática do estudo, ou seja, reportagens que em seu conteúdo trouxessem informações referentes ao processo de morte, morrer e a (re) organização de rituais fúnebres na pandemia. Utilizamos os critérios de exclusão: reportagens repetidas, informações sem aderência ao tema ou fugirem totalmente da temática apesar de conterem as palavras-chave. O ponto de saturação deste estudo seguiu o critério de intensidade e a qualidade das abordagens e das interações que emergiram das matérias jornalísticas e a profundidade com o fenômeno do luto e dos rituais fúnebres, para além da quantidade e repetição de ideias. O processo de busca se encerrou com a saturação dos dados, com 67 reportagens produtos da opinião de jornalistas e/ou entrevistados, conforme representado na Figura 1.

Foi utilizado o método de análise temática de conteúdo hermenêutico e dialético, proposto por Minayo ${ }^{23}$, iniciando pela leitura detalhada das reportagens selecionadas, para identificar os temas relativos aos impactos psicológicos gerados pela ausência de rituais fúnebres durante a pandemia; em seguida, foram categorizados em conteúdo para compor a análise temática e discussão dos dados. O processo de subjetivação da população 


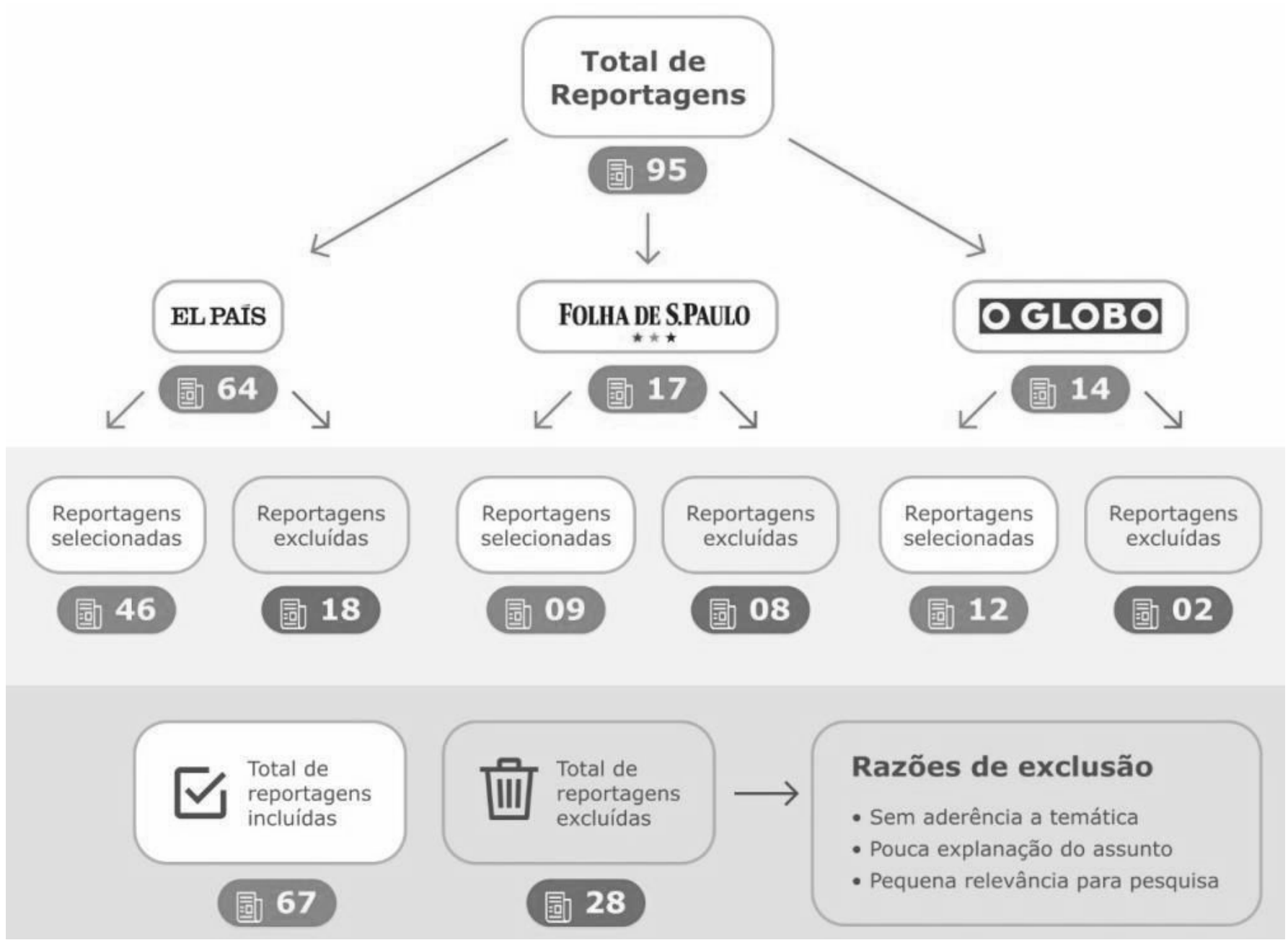

Figura 1. Fluxo síntese de fontes e reportagens da pesquisa sobre processo de luto diante da ausência de rituais fúnebres na pandemia de COVID-19. Elaborado pelas autoras. Florianópolis, 2021.

sobre o impacto psicológico da COVID-19 foi construído com o conteúdo das reportagens dos três jornais selecionados.

Considerando que este estudo é de cunho documental e utiliza, como fonte de coleta de dados, documentos de caráter público e de livre acesso à população de modo geral, justifica-se a realização do estudo sem a submissão em Comitê de Ética em Pesquisas Envolvendo Seres Humanos. A justificativa foi sustentada nos termos da Resolução 510, de 07 de abril de 2016 e em conformidade com a Lei 12.527/2011, uma vez que é pesquisa que utiliza informações de acesso e domínio público.

\section{RESULTADOS}

Da análise, foram elencadas duas categorias: "Os rituais fúnebres no contexto do isolamento social" e "Diferentes manifestações do luto".

\section{Rituais fúnebres em contexto de isolamento social}

Ilustramos essa temática, apontando algumas reportagens que trazem o impacto da pandemia no número alarmante de mortos e a incapacidade dos cemitérios para sustentar a nova demanda de enterros, e o que isso pode significar para as famílias que precisam enterrar seus mortos. "Não são números de mortes. São pessoas, histórias, afetos, memórias sagradas [...] Tantas covas abertas, uma ao lado da outra, são o retrato de uma pandemia avassaladora"24.

A pandemia cria situações inusitadas, entre elas a de mortes sem funerais. Como é possível ficarmos alheios a um rito de passagem tão ancestral, exclusivamente humano? Na natureza, nenhum outro ser chora os seus mortos e os reverencia no sepultamento (O Globo, Rio de Janeiro (Brasil), 27/04/2020 - Artigo: Antígona e Antares) ${ }^{25}$.

Todas as culturas estabelecem cerimônias e rituais para se despedirem de seus mortos. Este é um ato necessário para que as pessoas ligadas àquele que partiu possam manifestar sua dor, seu apreço, sua solidariedade de modo verbal e não verbal. O velório e o enterro são rituais clássicos que dão à família e 
aos amigos a oportunidade de estruturar a perda e se despedir daquele que se foi. Agora, mediante a pandemia, estão proibidos ou limitados, para evitar o contágio do vírus visto que a transmissão da COVID-19 pode perdurar por até 72 horas após a morte, além de funerais serem locais de muito contato e proximidade física. Abaixo destacamos, algumas matérias selecionadas nas quais mostram como os velórios e enterros estão sendo conduzidos visando a contenção da transmissão do vírus:

Seja pela falta de exames, pela demora nas análises ou pela ausência de protocolos para a realização de testes, quem está morrendo por parada respiratória ou por "causa não determinada" está sendo enterrado sob os mesmos critérios daqueles que morrem por complicações do coronavírus. Isso significa, dentre outras coisas, que não há chances de despedida. Não há velório —não só para evitar aglomerações, como também para evitar contato com o corpo possivelmente infectado- e o enterro é realizado com o caixão lacrado. [...] Quando a minha mãe entrou na sala para reconhecer o corpo, dentro do caixão era papelão, não era de cetim com flores, como ela tinha escolhido. Era por causa da COVID-19 (EI País, São Paulo (Brasil), 31/03/2020 - Mortes sem diagnóstico reforçam suspeitas de que estatísticas de coronavírus em São Paulo estão defasadas) ${ }^{26}$.

Há mais mortes do que o esperado, por uma pandemia que execra o mundo todo, e pela qual muitos não podem nem se despedir direito de parceiros, pais, tios, amigos, vivendo a pior dor de suas vidas, sem uma pausa para o ritual do luto. Caixões estão chegando fechados aos cemitérios, para evitar que familiares corram o risco de se contaminarem (El País, São Paulo (Brasil), 02/04/2020 - Cemitério em São Paulo. A foto que jamais gostaríamos de publicar) ${ }^{24}$.

Quando pensamos em ritual fúnebre, é muito possível que a imagem que nos venha à mente seja aquela que mais se alinha com nossa cultura e crença. As reportagens abaixo demonstram a função que os rituais cumprem no momento da partida, ao mesmo tempo que expõem o amplo espectro de diferentes significados e formas com que estes rituais são vividos dependendo da cultura do povo envolvido, lembrando-nos que o ritual fúnebre é realizado para além da forma que a cultura judaico-cristã ocidental o faz.

Agora, o vírus nos rouba tudo isso que traduz nossos laços de parentesco e amizade: visitar o enfermo, consolá-lo e animá-lo, preparar o corpo para o funeral, promover o velório, cumprir os rituais de enterro ou cremação, ver o caixão descer ao túmulo, orar em conjunto pelo falecido, e manifestar condolências e abraçar os mais afetados pela perda (O Globo, Rio de Janeiro (Brasil), 27/04/2020 - Artigo: Antígona e Antares) ${ }^{25}$.
Em diversos países da África, o combate à COVID-19 alterou tradições funerárias que mesclam rituais de religiões locais com elementos cristãos introduzidos pela colonização europeia do século 19 [...] O funeral na África é algo comunitário, não individual. Quando alguém morre, a comunidade toda sente o luto e divide a tristeza com a família do falecido, diz Sihawukele Ngubane, professor da Universidade de Kwazulu-Natal, na África do Sul (Folha de São Paulo, São Paulo (São Paulo), 16/05/2020 - Na África, funerais são tão importantes quanto casamentos. A pandemia os esvaziou) ${ }^{27}$.

Sem poder viver esses marcos de uma forma culturalmente condizente, que cumprem a função de organizadores emocionais para o luto, há mais chances de ocorrer complicações no processo de elaboração da perda. A perda em contexto de pandemia passa a ser algo vivenciado em solitude ou afastamento. As reportagens abaixo exemplificam esta nova experiência:

Maurício (nome fictício) perdeu a mãe para a COVID-19 no final de março. Ela teve acesso ao tratamento com cloroquina e respirador, mas não melhorou. Tinha 56 anos e nenhum doença prévia. "Meu pai foi sozinho reconhecer o corpo no hospital, sozinho até o cemitério e sozinho ao crematório. Não tiveram velório ou qualquer ritual fúnebre, mas Maurício espera poder realizar algo quando a pandemia passar, como uma missa de celebração da vida dela" (Folha de São Paulo, São Paulo (São Paulo), 14/04/2020 - Coronavírus priva famílias de importantes rituais do luto) ${ }^{28}$.

Hoje com 25 anos, Leonardo [sepultador do Cemitério São Francisco Xavier, no Caju, Rio de Janeiro] [...] Não está conseguindo se habituar à solidão dos enterros das vítimas da COVID-19. É difícil trabalhar acompanhado por um único parente do morto [...] - A ausência dos familiares é o mais triste. Quem vem para o enterro traz o sofrimento da família toda. O risco de contaminação mudou tudo. É algo anormal. (O Globo, Rio de Janeiro (Brasil), 14/05/2020 - Coronavírus: 'Ausência de familiares é o mais triste', conta sepultador do Caju sobre sua nova rotina no cemitério) $)^{29}$.

A importância do processo de luto não significa obrigatoriedade. Não podemos inferir que o luto precisa ser vivido para que as pessoas acometidas pela perda possam seguir suas vidas e que aqueles que não viveram o processo estão estagnadas. Queremos apontar que a vivência do processo de luto, em suas mais diversas formas e singularidades, é importante do ponto de vista de saúde mental. A reportagem destacada abaixo prevê impactos severos na saúde mental da população privada destes importantes rituais, destacando o que a ausência ou impossibilidade de readaptação pode acarretar. 
Segundo a psicóloga especializada no suporte ao luto, com treinamento em situações de emergências pós desastres e fundadora do Instituto Entrelaços, Erika Pallottino, a impossibilidade de acompanhar os doentes no hospital ou de se despedir caso o quadro se agrave cria um "traço traumático que é a morte súbita, inesperada". Ela afirma que especialistas no exterior dão uma perspectiva de dez anos de impacto da pandemia na saúde mental das pessoas, muito ocasionada pela resposta de luto (O Globo, Rio de Janeiro (Brasil), 25/04/2020 - Velório virtual, orações por aplicativo e grupos de apoio online: o 'novo' luto durante a pandemia do coronavírus) ${ }^{30}$.

Em tempos de pandemia e ausência de rituais fúnebres presenciais, identificamos as cerimônias virtuais como alternativas válidas para a concretização dessa etapa de despedida, também como maneira de prevenir possíveis transtornos advindos dos lutos interrompidos. As reportagens trazidas a seguir mostram como essa reestruturação de algo tão enraizado em nossa sociedade está sendo conduzida.

O cemitério Morada da Paz, em Natal, já realizava velórios virtuais desde 2001, permitindo que as despedidas pudessem ser realizadas de qualquer lugar do mundo. Mas essa espécie de missa online celebrada pelo padre Bianor é uma novidade que veio com a pandemia. "Surgiu a partir da necessidade de permanecer em casa para proteger os familiares, o ambiente onde se está, e também para proteger o celebrante" [...] "Eles me perguntaram se seria possível fazer uma oração, dar uma palavra de conforto, de forma virtual" (El País, São Paulo (Brasil), 25/05/2020 - "A sala de casa virou uma igreja": velórios online em tempos de coronavírus) ${ }^{31}$.

Nesse isolamento forçado por causa pandemia, o espanhol de 65 anos [Padre José Maria Ramirez, da Congregação Legionários de Cristo, no bairro da Gávea, Rio de Janeiro] tem recorrido, mais do que nunca, à tecnologia [...] Ele tem conduzido de dois a três sepultamentos virtuais por semana por um aplicativo de reunião. Foi o jeito que encontrou para que famílias possam se despedir de seus entes queridos nessa morte solitária causada pelo coronavírus [...] É duro não poder dar adeus a quem se ama, não abraçar pessoas queridas nessa hora. Cada morte tem um valor infinito. Como falar em estatística se é um amigo que se vai? Como proibir um filho de ir ao funeral de seu pai? (O Globo, Rio de Janeiro (Brasil), 31/05/2020 - Padre faz sepultamentos virtuais para vítimas de COVID-19: 'Como dizer a um filho que não pode ir ao funeral do pai?') $)^{32}$.

Nesta análise, destacamos a importância do ritual fúnebre para a vivência e elaboração da perda. Embora não exista forma padrão de despedida, principalmente diante de uma pandemia, acreditamos que também seja importante questionar em pesquisas futuras como o ritual fúnebre em meio a pandemia foi vivenciado por aqueles que não possuem internet ou acesso a meios que possam auxiliar na vivência desta etapa de despedida.

\section{Diferentes manifestações do luto}

Nesta segunda categoria, identificamos um total de vinte e duas reportagens nos três jornais pesquisados, abordando os mais diversos tipos de perdas. Ressaltamos que, ao longo desta pesquisa, deparamos-nos com diversos tipos de luto e buscaremos abordá-los aqui. Quando tratamos das mortes em pandemia, estamos visando famílias sendo ceifadas de uma vez, só tendo que vivenciar reestruturações rápidas. O luto pode assumir formas mais abrangentes que ultrapassam as mortes concretas de pessoas amadas, como ressaltado abaixo:

De certa maneira, todos já vivemos uma espécie de luto, em maior ou menor grau, pela enorme mudança social que enfrentamos. David Kessler afirma que isso é natural. "Temos micro e macro lutos. Obviamente o maior é a morte de alguém que amamos, mas também experimentamos lutos menores quando, por exemplo, perdemos o emprego ou nos separamos. Também sentimos luto pelo mundo que não existe mais. Um mês atrás o mundo que conhecíamos sumiu. As pessoas se sentem tristes, pesadas, não sabem por que choram, e eu digo que é o luto" (O Globo, Rio de Janeiro (Brasil), 25/04/2020 - Velório virtual, orações por aplicativo e grupos de apoio online: o 'novo' luto durante a pandemia do coronavírus) ${ }^{30}$

As experiências com a morte se tornam mais pessoais à medida que comunidades ou pessoas próximas são afetadas. A reportagem abaixo trata, além do luto antecipatório, a forma com que nossos lutos podem estar sendo 'organizados' e vivenciados neste período de pandemia e nos tempos que ainda virão:

Especialista em cuidar de quem está muito próximo ao final da vida, ela [a médica Ana Cláudia Quintana Arantes, geriatra e especialista em cuidados paliativos] já prevê que a humanidade passará por três tipos de luto. Além do luto real, das perdas objetivas, ela acrescenta o luto antecipatório - a percepção de que a morte está chegando. "Além disso, vamos ter um luto pela falta de consciência. Muitas pessoas vão se arrepender de não ter tido cuidado antes e vão pensar 'eu poderia ter ficado em casa, poderia ter convencido as pessoas a ficarem em casa", afirma. "Haverá arrependimento coletivo também", aposta (EI País, São Paulo (Brasil), 28/04/2020 - "Vamos ter um luto pela falta de consciência. Muitos vão se arrepender de não ter ficado em casa") ${ }^{33}$.

A dor da perda é sempre grande, mas, em tempos de coronavírus, se agiganta. Falta, entre parentes e amigos das vítimas, aquele abraço apertado que ajuda a consolar. [...] Nos 21 cemitérios da capital impera, além da tristeza, a solidão. A mesma que acomete os doentes, 
que, internados em isolamento completo, lutam pela vida sem direito sequer a uma rápida visita da família à UTI (O Globo, Rio de Janeiro (Brasil), 04/04/2020 - Sem velório e com caixões lacrados: coronavírus impõe isolamento até no luto e muda rotina em cemitérios) ${ }^{34}$.

Não podemos nem ter o luto. Teremos que vivê-lo outra hora. O corpo não pôde sequer ser levado para o IML (Instituto Médico-Legal), que nos respondeu que não recebem mais casos suspeitos de coronavírus, apenas os de mortes violentas - conta a jornalista e professora Raquel Lobão, nora de Maria Luiza (O Globo, Rio de Janeiro (Brasil), 31/03/2020 - 'Não podemos nem ter o luto', diz parente de mulher de 70 anos morta com suspeita de coronavírus na Rocinha) ${ }^{35}$.

O processo de luto alinhado à ausência de rituais tradicionais de cuidado ao corpo e homenagens e suas consequências é abordado nas reportagens a seguir:

A psicóloga e doutora em psicologia clínica Gabriela Casellato, sócia-fundadora do 4 Estações Instituto de Psicologia, especializado em luto, vê com preocupação as consequências da privação desses momentos. "O primeiro impacto é viver o luto abafadamente, isoladamente. Isso tende a impactar a duração do luto e sua intensidade. Outra questão é a falta da concretude, do corpo presente, podendo criar um aspecto ambíguo no enfrentamento da perda. A pessoa tende a ter mais dificuldades em seguir a vida, diz". "O luto de quem perdeu um ente querido para o vírus é ainda mais difícil [...] (Folha de São Paulo, São Paulo (Brasil), 14/04/2020 - Coronavírus priva famílias de importantes rituais do luto) ${ }^{28}$.

Acreditamos que a pandemia de COVID-19 tem o potencial catalisador de reestruturação das demandas vigentes e emergentes em saúde mental e do fenômeno do luto no Brasil, sendo a primeira vez na história que vivenciamos a ocorrência frequente de mortes nos mais diversos grupos sociais, levandonos a crer que este pode reverberar na forma com que a morte é encarada e estudada no país.

\section{DISCUSSÃo}

Os rituais relacionados com a morte, como os funerais, contextualizam espacialmente e temporalmente a experiência, servindo de auxílio para o rearranjo de papéis nas relações e continuidade do ciclo de vida. Além do mais, podem proporcionar respostas culturalmente condizentes capazes de fornecer à família a sensação de suporte necessário para ultrapassar o entorpecimento e confusão que a perda pode acarretar ${ }^{36}$.

Em um velório, a família tem a oportunidade de organizar a cerimônia da forma que acham que a pessoa que partiu poderia gostar, visando que a cerimônia faça sentido para o que a pessoa foi em vida, além de poder reunir pessoas queridas e ter a oportunidade de compartilhar a dor ao mesmo tempo que a alivia. Todos esses fatores contribuintes para a construção da 'narrativa da perda' estão suspensos durante a pandemia.

Essa iniciativa de rituais fúnebres na modalidade online é apontada pela cartilha da Fundação Oswaldo Cruz como estratégia remota de despedida perante a impossibilidade da proximidade. Pois, além de preencher as lacunas das homenagens aos mortos, reintegra, pelo menos em parte, a sensação de comunhão e compartilhamento que este momento pede, podendo também ajudar aqueles que continuam vivos ${ }^{14}$.

A cerimônia fúnebre serve para homenagear aquele que se foi, mas a continuidade da vida se dá através dos vivos. Assim, o ritual é benéfico para aqueles que participam dele, criando nele um momento e sensações de cumplicidade, compaixão e renovação, conectado com o sagrado e demarcando socialmente o início do luto necessário. Além do mais, o investimento na organização dos rituais, mesmo no formato online, pode amenizar possíveis sentimentos conflituosos, sendo este momento necessário para a elaboração psicológica, por ter contribuições saudáveis como: ajudar o indivíduo a se confrontar com a perda, permitir socialmente a entrada no processo de luto, possibilitando manifestar e compartilhar o seu sofrimento ${ }^{36}$.

O luto é a resposta à ruptura de um vínculo afetivo significativo, em que a dimensão do luto, junto de seu significado, é proporcional ao vínculo existente entre o enlutado e a pessoa que partiu. Entendemos o luto como uma vivência subjetiva e singular, experienciado de maneira única e diferente individualmente. Tal processo constituise como uma experiência dotada de significado, multideterminada e cultural. O processo do luto seria como ocupar um mundo desertificado por essa ausência. Aos poucos, vamos recompondo esse espaço, transformando-nos naquilo que se perdeu, que passa a viver em nós ${ }^{37}$. Porém, em meio a tantas perdas, a organização de um espaço emocional para lembrar das pessoas falecidas e internalizar suas ausências acaba sendo comprometido, ao mesmo tempo que este ponto é trazido como importante para aqueles que viveram poderem dar continuidade à suas vidas ${ }^{38}$.

O luto antecipatório tradicionalmente é uma resposta normal que ocorre com um paciente ou família diante de um diagnóstico terminal e costuma favorecer o preparo emocional. Porém, a pandemia tem contribuído para circunstâncias cada vez mais difíceis e o potencial para uma configuração de um luto antecipatório amplificado ${ }^{39}$. Essa condição de 'luto amplificado' é derivada da consciência diária, através dos veículos midiáticos e redes sociais, dos mapas globais de contágio e número de mortos que podem contribuir para a sensação de que o vírus 'está chegando' perto, aumentando o sofrimento por antecipação.

A complexidade do contexto da pandemia de COVID-19 pode impactar o processo de luto de diferentes formas. Primeiramente, como já foi citado anteriormente, destacamos que o luto antecipatório tende a ser afetado, pois estamos diante de um cenário em que pacientes internados podem ter um agravamento de quadro rapidamente, podendo vir a óbito antes que a família possa fazer sentido da iminência da perda. Em outros casos, o paciente sobrevive depois de vários dias internado, enquanto a família já estava vivenciando o luto antecipatório para o possível óbito, já que 
as Unidades de Tratamento Intensivo (UTIs) passaram a carregar o peso simbólico de serem os lugares que, uma vez adentrados, é possível que não se saia mais de lá, não se veja mais a família e a família não tenha mais contato com a pessoa que foi internada ${ }^{40}$. Como foi apontado na análise anterior, a sensação de que o falecido recebeu o ritual funerário que merecia ou a possibilidade de dar e receber conforto são marcadores importantes na elaboração das perdas por morte, e a ausência desses auxílios pode tornar o processo de luto ainda mais desafiador ${ }^{41}$.

A compreensão do luto como algo que está em nossa história passada, presente e futura destaca a preocupação em não considerar luto como uma doença ou em torná-lo uma experiência psiquicamente patológica, como foi tratado no início dos estudos sobre o tema ${ }^{13}$.

\section{CONCLUSÕES E IMPLICAÇÕES PARA A PRÁTICA}

O luto na pandemia é inevitável, pois a doença atinge todos os grupos, independente de quem nega a sua gravidade ou se considera inatingível por não acreditar nela. Este estudo possibilitou compreender modos de sensibilização e instrumentalização dos profissionais da saúde para o cuidado das pessoas em relação à morte e aquelas que vivem o luto por essas perdas.

É importante ressaltar que a morte e o luto, além de serem vividos individualmente de forma singular, também são vivenciados de formas socialmente diferentes, pois, no Brasil, atingem principalmente as pessoas em situação de vulnerabilidade social. Quando uma das diretrizes principais de proteção ao contágio pela COVID-19 é que aglomerações sejam evitadas e que a higienização dos espaços e pessoas sejam constantes, não podemos descartar a realidade brasileira em que milhares de pessoas vivem em situação de aglomeração nas suas próprias casas e com pouco ou nenhum acesso a saneamento básico e cuidados em saúde. As vidas perdidas que se amontoam, principalmente de camadas sociais desfavorecidas, marginalizadas, em que o poder público se ausenta para dar condições dignas de vida. Apesar de todos os esforços muito benéficos de acolher as pessoas em isolamento em meio à perda, ainda não é possível saber quais serão as consequências das ausências deixadas nos processos para a elaboração da perda que, como pontuamos, já começa antes da morte em si.

Acreditamos que, em termos de implicações para a prática, este estudo contribui para socializar a gravidade dos efeitos que a pandemia acarreta para as nossas vidas. A memória de sofrimento e perda permanece por longo período mesmo após a produção de estratégias medicamentosas, vacina e a imunidade da população. Assim, este estudo traz reflexões teóricas que se consubstanciam em aplicação prática na saúde mental e no acolhimento daqueles passando por processos de luto decorrentes da pandemia, reflexos pós-pandêmcios. Um discurso muito disseminado é o desejo pelo 'retorno à normalidade', quando, na verdade, a normalidade anterior não poderá voltar depois de mais de quatrocentos mil brasileiros mortos, e quando você, caro leitor, ler este artigo, esta realidade será constatada por um número ainda maior de mortes.
As limitações deste estudo se mostram no próprio distanciamento físico de trazer à realidade os rituais fúnebres sob depoimentos das pessoas enlutadas. $\mathrm{O}$ que podemos fazer é construir estratégias de cuidado e adaptação diante desse novo cenário, em especial no campo da saúde mental. Talvez podemos ter a possibilidade de dar voz, neste estudo, por meio de entrevistas aos familiares, à sociedade vitimada pelo luto, pela dor e sofrimento do adeus sem a possibilidade da despedida.

\section{CONTRIBUIÇÕES DOS AUTORES}

Concepção do estudo. Maria Eduarda Padilha Giamattey. Coleta ou produção dos dados. Maria Eduarda Padilha Giamattey.

Análise de dados. Joselma Tavares Frutuoso; Maria Lígia dos Reis Bellaguarda; Ivânia Jann Luna.

Interpretação dos resultados. Joselma Tavares Frutuoso; Maria Lígia dos Reis Bellaguarda; Ivânia Jann Luna.

Redação e revisão crítica do manuscrito. Joselma Tavares Frutuoso; Maria Lígia dos Reis Bellaguarda; Ivânia Jann Luna. Aprovação da versão final do artigo. Maria Eduarda Padilha Giamattey; Joselma Tavares Frutuoso; Maria Lígia dos Reis Bellaguarda; Ivânia Jann Luna.

Responsabilidade por todos os aspectos do conteúdo e a integridade do artigo publicado. Maria Eduarda Padilha Giamattey; Joselma Tavares Frutuoso; Maria Lígia dos Reis Bellaguarda; Ivânia Jann Luna.

\section{EDITOR ASSOCIADO}

\author{
Antonio José Almeida Filho (i)
}

\section{EDITOR CIENTÍFICO}

\author{
Ivone Evangelista Cabral (D)
}

\section{REFERÊNCIAS}

1. Li H, Liu L, Zhang D, Xu J, Dai H, Tang $N$ et al. SARS-CoV-2 and viral sepsis: observations and hypotheses. Lancet. 2020;395(10235):1517-20. http://dx.doi.org/10.1016/S0140-6736(20)30920-X. PMid:32311318.

2. Ho C, Chee C, Ho R. Mental health strategies to combat the psychological impact of COVID-19 beyond paranoia and panic. Annals of the Academy of Medicine. 2020;49(1):1-3. PMid:32200399.

3. Organização Mundial da Saúde. WHO Director-General's opening remarks at the media briefing on COVID-19 [Internet]. 2020 [citado 2021 maio 7]. Disponível em: https://www.who.int/director-general/speeches/ detail/who-director-general-s-opening-remarks-at-the-media-briefingon-covid-19---11-march-2020

4. Spreeuwenberg P, Kroneman M, Paget J. Reassessing the global mortality burden of the 1918 influenza pandemic. Am J Epidemiol. 2018;187(12):2561-7. http://dx.doi.org/10.1093/aje/kwy191. PMid:30202996.

5. Vidal-Alaball J, Acosta-Roja R, Pastor Hernández N, Sanchez Luque $\mathrm{U}$, Morrison D, Narejos Pérez $\mathrm{S}$ et al. Telemedicine in the face of the COVID-19 pandemic. Aten Primaria. 2020;52(6):418-22. http://dx.doi. org/10.1016/j.aprim.2020.04.003. PMid:32402477.

6. Aquino EML, Silveira IH, Pescarini JM, Aquino R, Souza-Filho JA, Rocha AS et al. Social distancing measures to control the COVID-19 pandemic: potential impacts and challenges in Brazil. Cien Saude 
Colet. 2020 Jun;25(Supl. 1):2423-46. http://dx.doi.org/10.1590/141381232020256.1.10502020.

7. Santos TBS, Andrade LR, Vieira SL, Duarte JA, Martins JS, Rosado LB et al. Hospital contingency in coping with COVID-19 in Brazil: governmental problems and alternatives. Cien Saude Colet. 2021 Apr;26(4):1407-18. http://dx.doi.org/10.1590/1413-81232021264.43472020.

8. American Psychological Association. Social science and the COVID-19 vaccines [Internet]. 2021 [citado 2021 maio 7]. Disponível em: https:// www.apa.org/monitor/2021/03/covid-19-vaccines

9. Souza JB, Heidemann ITSB, Geremia DS, Madureira VSF, Bitencourt JVOV, Tombini LHT. Pandemic and immigration: haitian families in facing COVID-19 in Brazil. Esc Anna Nery. 2020;24(spe):e20200242. http:// dx.doi.org/10.1590/2177-9465-ean-2020-0242.

10. Brooks SK, Webster RK, Smith LE, Woodland L, Wessely S, Greenberg $\mathrm{N}$ et al. The psychological impact of quarantine and how to reduce it: rapid review of the evidence. Lancet. 2020;395(10227):912-20. http:// dx.doi.org/10.1016/S0140-6736(20)30460-8. PMid:32112714.

11. Menezes RA, Gomes EC. "Seu funeral, sua escolha": rituais fúnebres na contemporaneidade. Rev Antropol. 2011;54(1):88-131. https://doi. org/10.11606/2179-0892.ra.2011.38585.

12. Papalia D, Olds SW, Feldman RD. Desenvolvimento humano. 10. ed. Porto Alegre: Artmed; 2009.

13. Fundação Oswaldo Cruz. Saúde mental e Atenção Psicossocial na Pandemia COVID-19: Processo de luto no contexto da COVID-19 [Internet]. 2020 [citado 2021 maio 7]. Disponível em: http://renastonline. ensp.fiocruz.br/recursos/saude-mental-atencao-psicossocial-pandemiacovid-19-processo-luto-contexto-covid-19

14. Franco MHP. Porque estudar o luto na atualidade? In: Franco MHP, organizador. Formação e rompimento de vínculos: o dilema das perdas na atualidade. 1. ed. São Paulo: Summus Editorial; 2010. p. 17-42.

15. Van Gennep A. Os ritos de passagem. 2. ed. Petrópolis: Vozes; 2011.

16. Bitencourt JVOV, Meschial WC, Frizon G, Biffi P, Souza JB, Maestri E. Nurse's protagonism in structuring and managing a specific unit for COVID-19. Texto Contexto Enferm. 2020;29:e20200213. http://dx.doi. org/10.1590/1980-265x-tce-2020-0213.

17. Bayard JP. Sentido oculto dos ritos mortuários: morrer é morrer? 1. ed. São Paulo: Paulus; 1996.

18. Araújo CM, Oliveira MCSL, Rossato M. O sujeito na pesquisa qualitativa: desafios da investigação dos processos de desenvolvimento. Psicol, Teor Pesqui. 2017;(33):e33316. https://dx.doi.org/10.1590/0102.3772e33316.

19. Kripka R, Scheller M, Bonotto DL. Pesquisa documental: considerações sobre conceitos e caraterísticas na pesquisa qualitativa. Atas [Internet]. 2015; [citado 2021 maio 7];2:243-7. Disponível em: https://proceedings. ciaiq.org/index.php/ciaiq2015/article/view/252/248

20. Flick U. Introdução à pesquisa qualitativa. 3. ed. Porto Alegre: Artmed; 2009.

21. Padilha MI, Bellaguarda MLR, Nelson S, Maia ARC, Costa R. O uso das fontes na condução da pesquisa histórica. Texto Contexto Enferm. 2017;26(4):e2760017. http://dx.doi.org/10.1590/0104-07072017002760017.

22. Jesus DSV. O Brasil no BRICS, segundo a Folha de S. Paulo e O Globo (2011-2013). Aurora. 2014;20(7):51-81. https://doi.org/10.23925/19826672.

23. Minayo MCS. O desafio do conhecimento: pesquisa qualitativa em saúde. 14. ed. São Paulo: Hucitec; 2014.

24. Jiménez C. Cemitério em São Paulo: a foto que jamais gostaríamos de publicar. El País [Internet]. 2020 abr 2 [citado 2021 maio 17]. Disponível em: https://brasil.elpais.com/opiniao/2020-04-03/cemiterio-em-saopaulo-a-foto-que-jamais-gostariamos-de-publicar.html

25. Betto F. Antígona e Antares. O Globo [Internet]. 2020 abr 27 [citado 2021 maio 17]. Disponível em: https://oglobo.globo.com/sociedade/ artigo-antigona-antares-24395691

26. Rossi M. Mortes sem diagnóstico reforçam suspeitas de que estatísticas de coronavírus em São Paulo estão defasadas. El País [Internet]. 2020 mar 31 [citado 2021 maio 17]. Disponível em: https://brasil.elpais.com/ politica/2020-03-31/mortes-sem-diagnostico-levantam-suspeita-desubnotificacao-de-casos-do-coronavirus-em-sao-paulo.html

27. Perassolo J, Ferraro M. Na África, funerais são tão importantes quanto casamentos: a pandemia os esvaziou. Folha de São Paulo [Internet] 2020 maio 16 [citado 2021 maio 17]. Disponível em: https://www1.folha. uol.com.br/mundo/2020/05/na-africa-funerais-sao-tao-importantesquanto-casamentos-a-pandemia-os-esvaziou.shtml

28. Appel C. Coronavírus priva famílias de importantes rituais do luto. Folha de São Paulo [Internet]. 2020 abr 14 [citado 2021 maio 17]. Disponíve em: https://www1.folha.uol.com.br/equilibrioesaude/2020/04/coronaviruspriva-familias-de-importantes-rituais-do-luto.shtml

29. Ribeiro G. Coronavírus: 'Ausência de familiares é o mais triste' conta sepultador do Caju sobre sua nova rotina no cemitério. O Globo [Internet] 2020 maio 14 [citado 2021 maio 17]. Disponível em: https://oglobo. globo.com/rio/coronavirus-ausencia-de-familiares-o-mais-triste-contasepultador-do-caju-sobre-sua-nova-rotina-no-cemiterio-24425947

30. Tatsch C.Velório virtual, orações por aplicativo e grupos de apoio online: o 'novo' luto durante a pandemia do coronavírus. O Globo [Internet]. 2020 abr 25 [citado 2021 maio 17]. Disponível em: https://oglobo.globo.com/ sociedade/coronavirus/velorio-virtual-oracoes-por-aplicativo-grupos-deapoio-online-novo-luto-durante-pandemia-do-coronavirus-24385878

31. Rossi M. "A sala de casa virou uma igreja": velórios online em tempos de coronavírus. El País [Internet]. 2020 maio 25 [citado 2021 maio 17] Disponível em: https://brasil.elpais.com/brasil/2020-05-25/a-sala-decasa-virou-uma-igreja-velorios-online-em-tempos-de-coronavirus.html

32. Fortuna M. Padre faz sepultamentos virtuais para vítimas de Covid-19: 'Como dizer a um filho que não pode ir ao funeral do pai?'. O Globo [Internet]. 2020 maio 31 [citado 2021 maio 17]. Disponível em: https:// oglobo.globo.com/cultura/padre-faz-sepultamentos-virtuais-paravitimas-de-covid-19-como-dizer-um-filho-que-nao-pode-ir-ao-funeraldo-pai-24455253

33. Rossi M. Coronavírus: "Vamos ter um luto pela falta de consciência Muitos vão se arrepender de não ter ficado em casa". El País [Internet] 2020 abr 28 [citado 2021 maio 17]. Disponível em: https://brasil.elpais. com/politica/2020-04-20/ana-claudia-quintana-arantes-havera-umarrependimento-coletivo-tambem.html

34. Amorim D. Sem velório e com caixões lacrados: coronavírus impõe isolamento até no luto e muda rotina em cemitérios. O Globo [Internet] 2020 abr 4 [citado 2021 maio 17]. Disponível em: https://oglobo. globo.com/rio/sem-velorio-com-caixoes-lacrados-coronavirus-impoeisolamento-ate-no-luto-muda-rotina-em-cemiterios-1-24350944

35. Nunes M. Nova Iguaçu decreta calamidade pública com $80 \%$ dos leitos hospitalares já ocupados. O Globo [Internet]. 2020 mar 31 [citado 2021 maio 17]. Disponível em: https://oglobo.globo.com/rio/novaiguacu-decreta-calamidade-publica-com-80-dos-leitos-hospitalaresja-ocupados-1-24341264

36. Souza CP, Souza AM. Rituais fúnebres no processo do luto: significados e funções. Psicol, Teor Pesqui. 2019;35:e35412. http://dx.doi. org/10.1590/0102.3772e35412.

37. Braz MS, Franco MHP. Profissionais paliativistas e suas contribuições na prevenção de luto complicado. Psicologia. 2017;37(1):90-105. http:// dx.doi.org/10.1590/1982-3703001702016.

38. Worden JW. Grief counseling and grief therapy: a handbook for the mental health practitioner. 5th ed. Nova York: Springer; 2018. http:/ dx.doi.org/10.1891/9780826134752.

39. Wallace CL, Wladkowski SP, Gibson A, White P. Grief During the COVID-19 Pandemic: considerations for palliative care providers. $J$ Pain Symptom Manage. 2020;60(1):e70-6. http://dx.doi.org/10.1016/j. jpainsymman.2020.04.012. PMid:32298748.

40. Crepaldi MA, Schmidt B, Noal DS, Bolze SDA, Gabarra LM. Terminalidade, morte e luto na pandemia de COVID-19: demandas psicológicas emergentes e implicações práticas. Estud Psicol. 2020;37:e200090.

41. Ingravallo F. Death in the era of the COVID-19 pandemic. Lancet Public Health. 2020;5(5):e258. http://dx.doi.org/10.1016/S2468-2667(20)30079-7. PMid:32247328.

\footnotetext{
a Extraído da dissertação de Mestrado intitulada "Processo de Luto diante da Ausência de Ritual Fúnebre na Pandemia da COVID-19: análise documenta jornalismo online", apresentada ao Programa de Pós-Graduação em Saúde Mental e Atenção Psicossocial da Universidade Federal de Santa Catarina, em 2020, de autoria de Maria Eduarda Padilha Giamattey, sob a orientação de Joselma Tavares Frutuoso
} 